\title{
OBSERVATIONS ON PARTIAL REMOVAL OF THE POST-CENTRAL GYRUS FOR PAIN
}

BY

\author{
WALPOLE LEWIN and C. G. PHILLIPS \\ From the Nuffield Department of Surgery and the University Laboratory of Physiology, Oxford
}

The role of the cerebral cortex in the conscious appreciation of pain has interested neurologists for many years. Head and Holmes (1911) considered that pain entered consciousness at thalamic level, and more recently Penfield (1947) stated that "... no removal of cortex anywhere can prevent pain from being felt and only very rarely does a patient use the word pain to describe the result of cortical stimulation", and, he goes on, "it is obvious therefore that the pathway of pain conduction reaches the thalamus and consciousness without essential conduction to the cortex". Adrian (1941) found that no impulses reached the sensory cortex in response to noxious or thermal stimulation at the periphery in the rabbit, cat, and monkey. On the other hand, a considerable body of evidence would suggest that there is central representation of pain in the cortex, and this work has been summarized recently by Marshall (1951) who, in presenting further evidence from 11 cases of cortical wounds followed by impairment of pain and temperature sense, advanced the hypothesis that the final elaboration of sensory impulses depends on mutual activation of thalamus and cortex.

Electrical stimulation of the cortex has yielded equivocal results. In Cushing's (1909) two cases stimulation of the post-central gyrus was painless, and Foerster (1936) reported paraesthesiae but seldom pain. Penfield and Boldrey (1937) recorded only 11 instances out of well over 800 responses to electrical stimulation where the word "pain" had been used by the patient to describe the cortical sensation. Recently, however, Horrax (1946) stimulated the post-central gyrus in four patients suffering from painful states and elicited pain in three. To explain the apparent discrepancy between his results and those of Penfield and Boldrey, Horrax concluded that he was probably using too strong a current, since in the motor cortex the same current caused convulsions. Stone (1950) also recorded one case where stimulation of the sensory cortex produced pain in the phantom leg.

In this paper we wish to record three cases in which partial resection of the post-central gyrus was undertaken for the relief of pain. In the first patient the pain developed during an unusual, prolonged, sensory painful aura in traumatic epilepsy, the second patient had intractable pain in a phantom foot, and the third had a painful thigh stump. In all three, electrical stimulation of the appropriate area of the post-central gyrus reproduced the pain complained of by the patient and relief followed the removal of this area of cortex.

\section{Results of Stimulation}

The operations were conducted under local analgesia. Monopolar stimulation was used. The stimulator gave negative square pulses of current, the strength, frequency, and duration of which could be independently controlled. The position of the motor cortex was first identified by stimulation and then the post-central gyrus was explored. With varying parameters, different thresholds of stimulation in the motor and sensory cortex were established. Thus in Case 3, using single shocks of strength $1.5 \mathrm{~mA}$ and duration $5.0 \mathrm{~m} . \mathrm{sec}$., flexion and adduction of the thumb with abduction of the index was produced over a wide area of the motor cortex (Fig. 1B). Stimulation nearer the midline within this area at the same strength produced flexion of the wrist and supination, still, however, with the basic thumb-index response. The remainder of the motor area was unresponsive to these shocks. It was not possible to produce leg movement until the current was increased to $2.5 \mathrm{~mA}$, and then in this case, still using single shocks, strong flexion of the hip was produced. These observations on the motor cortex were incomplete, since the primary concern was the sensory cortex and there was a limit to the time the patient would cooperate 
accurately in responses to stimulation before he tired. Nevertheless, it does suggest that further observations on the unanaesthetized human cortex with varying parameters may yield results not dissimilar from those obtained in the baboon by Liddell and Phillips (1950).

With single shocks no response was obtained from the postcentral gyrus and the threshold seemed much higher than for the motor cortex. In all three cases a frequency of $50 \mathrm{c} / \mathrm{s}$ was required to produce a response. In Case 2, where it was possible to explore the sensory cortex more fully, pain in the phantom ankle was produced with a current of $50 \mathrm{c} / \mathrm{s}$ and
$2 \mathrm{~mA}$. Working over the surface of the postcentral gyrus in the hand area with the same current, no response was obtained, but stimulation of the posterior bank of the Rolandic fissure in this region resulted in a sensation as if the hand had moved upwards, although no actual movement was observed. Again, medial to the area giving rise to pain, stimulation in the fissure resulted in a sensation of pins and needles in the toes (Fig. 2). The pain response therefore was localized, and it may be that in these painful states the corresponding area of cortex becomes conditioned so that its activation produces pain.

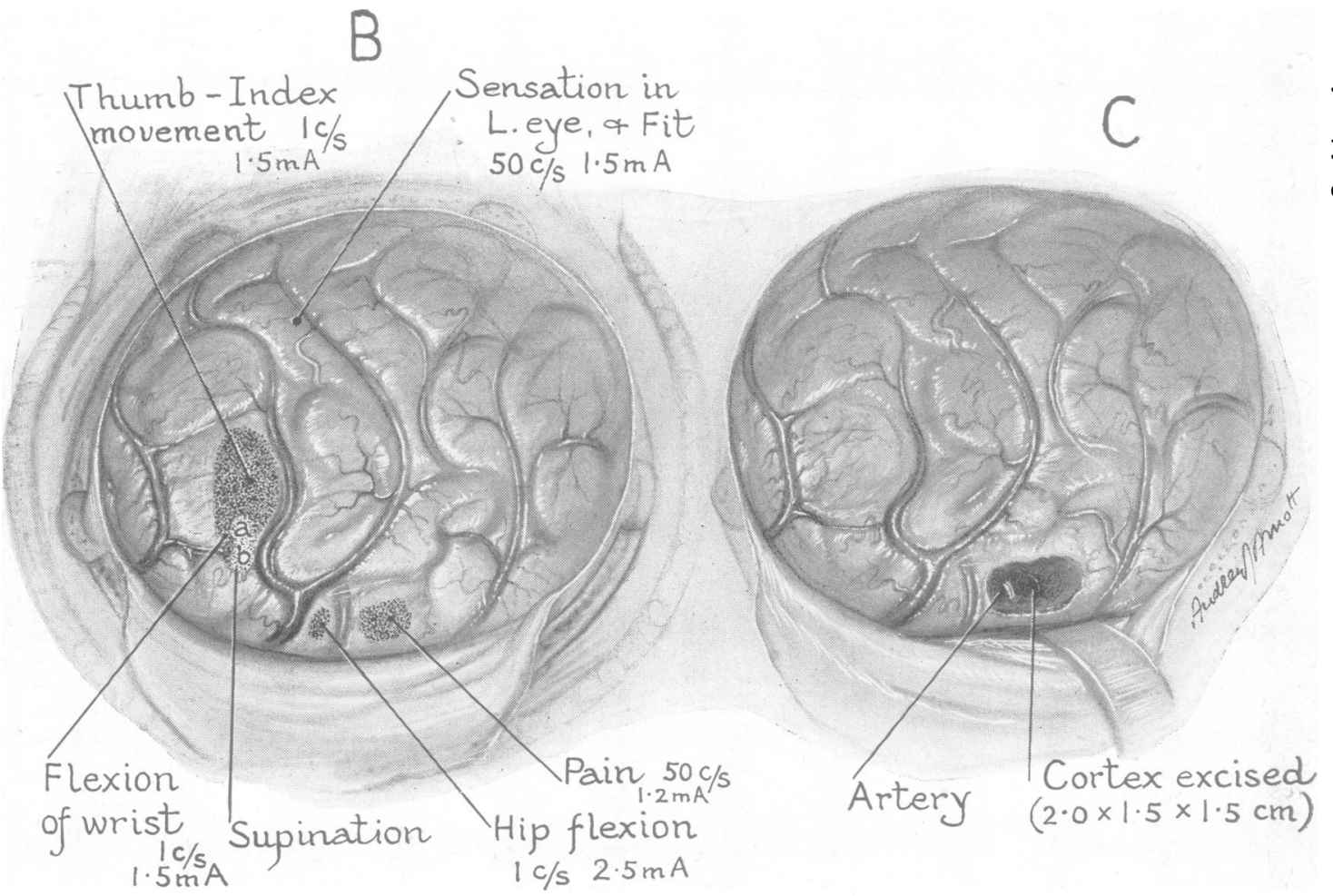

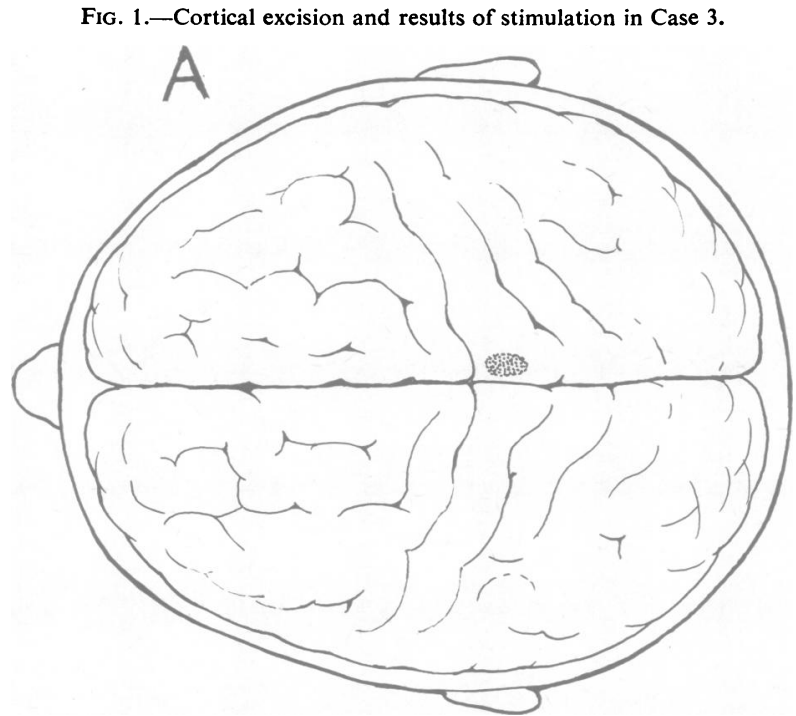




\section{Case Reports}

Case 1 (H.N. 19059). - This soldier, aged 28 years, was injured on May 1, 1942, and sustained a penetrating gunshot wound in the right parietal region. He was taken prisoner and did not receive definitive treatment of his wound for five weeks. His residual disability consisted of an incomplete left lower quadrantic hemianopia and a little weakness of the left hand with minimal cortical sensory loss.

The patient had his first epileptic fit the day after his injury, the second five months later, and thereafter until his admission to the Military Hospital (Head Injuries), Oxford, in February, 1948, an attack at least every two months, sometimes two within a week. The attacks were characterized by a long, painful, sensory aura lasting five minutes before he lost consciousness. At the onset the left hand would be drawn into the side and the fingers begin to tingle; this sensation rapidly travelled up the outside of the arm to the shoulder, increasing in intensity and accompanied by a deep, gnawing pain in the wrist and hand. The forearm would feel as if it was being alternately blown up and deflated. By this time the patient said he would be confused but still able to lie down to await the attack and also to ask someone to place a prop between his teeth. The pain progressed to involve the face, the left eye, and finally the left eyebrow, at which stage he would lose consciousness. Associated with the later phases of the pre-ictal stage, objects in front of him rotated at increasing speed anticlockwise and were coloured red or yellow.
He volunteered the information that the pain was torture, that he dreaded it more than the actual fit, and had even contemplated asking to have his arm amputated. The convulsion was generalized and was often followed by a pronounced automatism lasting two hours or so.

Examination in February, 1948, revealed the residual hemisphere signs mentioned above and a right parietal bone defect. An air encephalogram showed dilatation of the right ventricle with a traction diverticulum towards the bone defect.

On February 25, 1948, under local analgesia, a right lateral flap was turned down. The dural scar, $7 \cdot 5 \times$ $2.5 \mathrm{~cm}$., was separated from the ventricular cyst by only a few millimetres' thickness of glial scar, and in opening the dura the ventricular diverticulum was entered immediately. The dural scar was therefore excised. The anterior extremity of the diverticulum was just behind the post-central gyrus and its lower limit lay $1 \mathrm{~cm}$. above the line of the Sylvian fissure. The walls of the diverticulum were perfectly smooth except at one place in the anterior wall where in the depths was a small piece of greyish, congested cortex, $1.0 \times 0.5 \mathrm{~cm}$., across which ran a vein. Posteriorly the cyst communicated directly with the lateral ventricle through a small hole, through which the choroid plexus was drawn up. The rest of the exposed brain looked normal.

On stimulation no response was obtained from the cortex around the diverticulum but as soon as the piece of cortex in its anterior wall was stimulated the patient experienced tingling in the fingers of the left hand and

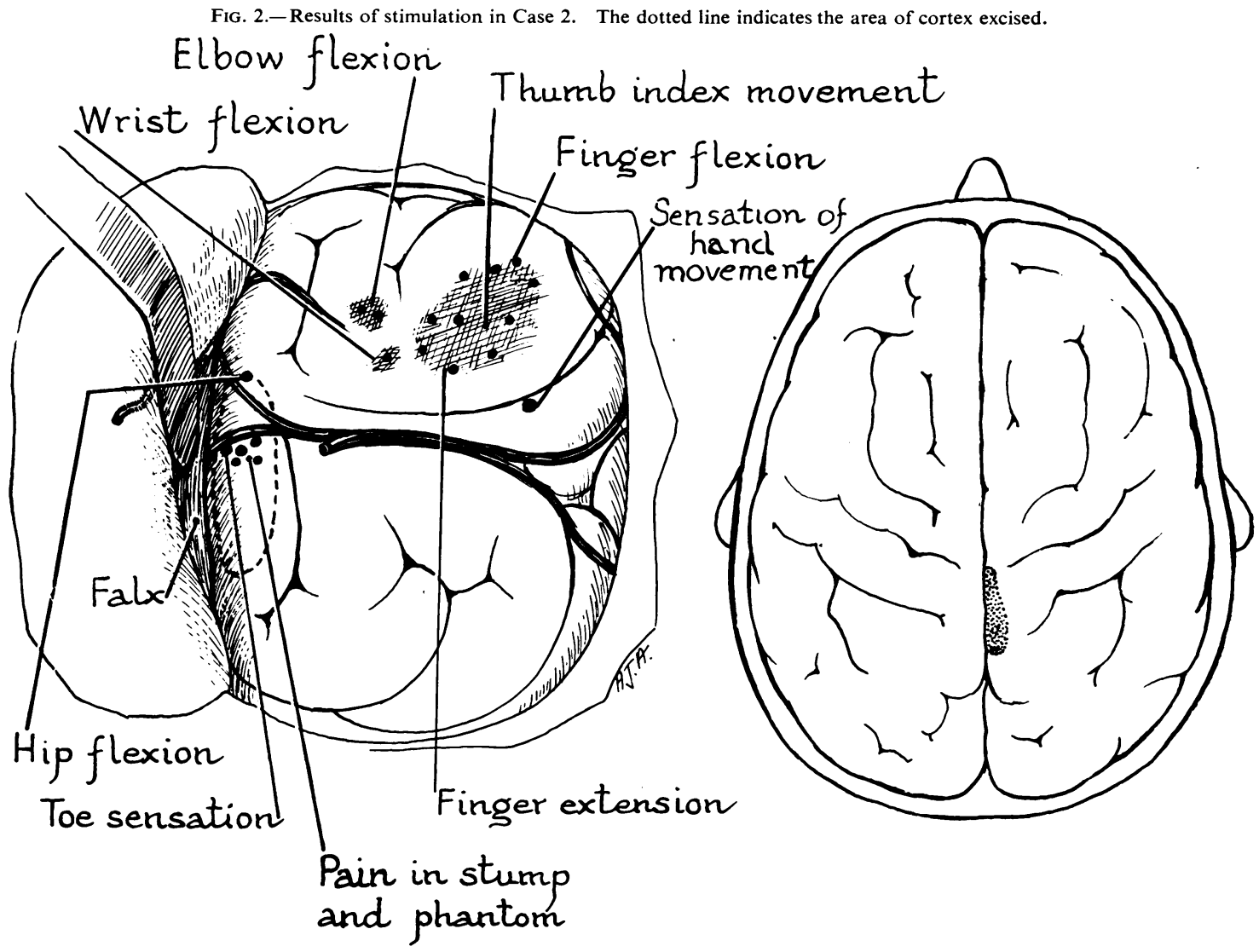


pain in the hand exactly reproducing the onset of one of his attacks. From the lower part of this area, tingling in the cheek was produced. These responses were elicited on four successive occasions. Going well forward on to the normal cortex, stimulation resulted in movement of the left eye and a generalized epileptic fit. The abnormal piece of cortex was now excised to a depth of $2 \mathrm{~mm}$., at which level the white matter lining the cyst wall was encountered.

Post-operatively there was no increase in weakness of the left hand but there was an increased sensory deficit, with complete astereognosis and some impairment of joint position sense. On the second post-operative day the patient had three fits. The aura in these was similar to those experienced before the operation but without the severe, gnawing pain.

When seen in January, 1952, four years after the operation, the patient was at work and said he had only had one fit since leaving hospital, in December, 1949. The fingers began to tingle in the same way as before but the aura was much shorter and unaccompanied by pain. He said that the sensation in the left hand had improved steadily for one year after leaving hospital. On examination, he was found to have complete recovery of position sense but stereognosis was still impaired and two-point discrimination was not quite as well appreciated in the left hand as in the right.

Case 2 (H.N. 22566). - This patient, a pensioner aged 66 years, had a left thigh amputation performed in 1916 after a torpedo explosion while on active service. From the outset he had a phantom limb but the only pain he experienced was a jerking in the ankle and heel about once or twice a week, sensations which were never incapacitating and did not interfere with his work as a boot repairer. This state of affairs continued until 1941 when he noticed that these sensations were becoming more frequent and distinctly painful. The stage was soon reached when the pain was interfering with his sleep. The pain was confined entirely to the phantom foot and described as a tearing pain around the heel and inside of the ankle, as though someone were trying to pull the ankle off. The pain also radiated into the toes. He had not experienced shortening of the phantom and when he stood up he felt the knee extended and the ankle dorsiflexed with the heel on the ground. Over the seven years up to the time of his admission in March, 1951, he had had numerous local operations and injections, including spinal analgesia, in an attempt to relieve the pain, without even temporary relief. He never had an undisturbed night's sleep and was on heavy barbiturate sedation. In 1950 a carcinoma of the rectum was discovered and treated by excision.

On admission the patient was in severe pain but cooperative and there did not appear to be any functional overlay. He looked much older than his years and was arterio-sclerotic, but despite his age and general health the severity of his pain demanded further treatment. In view of the failure of peripheral operations and analgesia, ablation of the sensory leg area was proposed. At operation on March 15, 1951, under local analgesia, the motor cortex was identified and movements obtained from the hand, elbow, and finally the stump. Stimulation of the post-central gyrus near the vertex just against the falx immediately produced his pain, and this observation was repeated several times. This response was obtained over an area measuring $1 \mathrm{~cm}$. in diameter. This area was excised but it had no effect on the pain. Stimulation deep in the anterior cut edge, that is on the posterior bank of the Rolandic sulcus, still produced pain. The excision was gradually extended until an area of sensory cortex, $3.0 \times 1.0 \times 1.0 \mathrm{~cm}$., was removed. Medially the excision extended down the medial side of the hemisphere for $1 \mathrm{~cm}$. (Fig. 2). At this stage the patient was not quite free of pain but was considerably improved and it was decided therefore to terminate the operation.

Immediately after the operation the patient still had some pain in the phantom on direct questioning but no longer complained of it spontaneously and slept at night without sedatives. Neurologically there was no weakness in the stump or sensory impairment. The residual pain died away in the early post-operative weeks and the patient returned home. There for nearly six months he was completely free from pain, slept well, and got about on his artificial leg. He still had his phantom limb and toward the end of this time noted some return of pain. He was readmitted to hospital at the end of September, 1951, for review. Under observation it was obvious that there had been considerable improvement ; he looked well, slept well, and such pain as he had was controlled with aspirin.

Case 3 (H.N. 25642). - This pensioner, aged 58 years, sustained a gunshot wound of the left leg in 1919; two years later a mid-thigh amputation was performed for non-union of the fractured femur. Thereafter he was perfectly well for 27 years and had no phantom. Then in 1946, for no apparent reason, pain began in the stump. It was localized to an area on the outside of the stump and the pain varied from a surface prickling sensation, of itself sufficient to keep him awake at night, to a severe, gnawing and gripping pain in the stump. At first intermittent, it had gradually become more persistent until at the time of his admission in September, 1951, the pain had been present without respite for seven months and the patient was beginning to feel desperate about the situation. He was an excellent type of man, who, despite his pain, had continued at his work as a ticket collector on the railway. Over the last five years he had had numerous local operations on the stump, a cordotomy in January, 1950, and a spinal analgesic in October, 1950. The cordotomy had relieved him for three weeks but the spinal analgesic gave no relief at all. On examination, he was in good physical condition and the stump was sound and strong. There was hemihypoalgesia to pin-prick and temperature sense extending over the stump and up to the lower costal margin on the left side corresponding to the cordotomy.

At operation in November, 1951, the cortex was exposed under local analgesia through a right lateral flap. The motor cortex was defined by stimulation, and 
then precisely posterior to the motor region from which stimulation had produced flexion of the stump, stimulation resulted in a severe gripping pain in the stump, according to the patient, the same for which he was seeking relief. This response was reproduced several times. The pain induced was followed by jactitation of the stump. An area of cortex about $1 \mathrm{~cm}$. in diameter was excised without, however, influencing his pain. At the bottom of the cavity so produced was the grey matter of the posterior lip of the central sulcus, and on pinching a small vessel here with forceps, the pain was again produced. As this grey matter was sucked away the pain disappeared. The final excision measured $2.0 \mathrm{~cm}$. in the sagittal plane, $1.5 \mathrm{~cm}$. in the coronal plane, and was $1.5 \mathrm{~cm}$. deep (Fig. 1C). It did not extend on to the medial side of the hemisphere, although this formed the medial wall of the cavity and the cortex here had been undercut by the excision.

Following operation the patient had some superficial tingling in the stump which died away after a few days. Five days after operation he awoke with a burning pain in the stump quite different from any pain he had had previously, and this was accompanied a few hours later by numbness in the ring finger of the left hand and slight clumsiness of the hand. All these symptoms cleared up within 17 hours. On the fifth day he had a brief attack of numbness in the left ring finger lasting 10 minutes. Thereafter there were no further incidents, and when discharged home five weeks after operation he had been completely relieved of his pre-operative pain although he was having a few aching pains over a small area of the stump which were insignificant by day but worried him at night. There had been no change in the motor or sensory state of the stump following the operation.

\section{Comment}

Whether removal of these small areas of sensory cortex will permanently relieve pain is still undecided. Some published reports on the results of this operation for phantom limb pain up to two years after operation (de Gutiérrez-Mahoney, 1944 ; Echols and Colclough, 1947; Stone, 1950) are encouraging, and although there are disappointments in trying to relieve this type of pain (Lhermitte and Puech,1946 ; de Gutiérrez-Mahoney, 1948), and more especially in other painful states (Horrax, 1946 ; Rowbotham, 1946), it would perhaps be surprising if this were not so. Only that part of the sensory representation which produces pain on electrical stimulation is removed by this operation, with, in some cases, a small area of cortex immediately adjacent. The strychninization experiments of Dusser de Barenne (1924), Penfield's observations on the human cortex, and Woolsey's work $(1943,1947)$ on the second sensory cortex suggest that the pre-central gyrus and cortex near the Island of Reil are also concerned in somatic sensory representation.
The attraction of such an operation is the possibility of relieving pain without producing any marked permanent motor or sensory deficit or personality change. The possible sequel is the production of epilepsy but so far there is no record of this complication. If further experience is favourable, the place of the operation in treatment will have to be considered in relation to alternative operations on the frontal lobes.

The results of stimulation in these three cases are in contrast with the observations of Penfield and others, and might appear at first sight to lend support to the contention that there is cortical representation of pain. However, it has to be remembered that these responses were obtained in patients experiencing severe spontaneous pain. All we may conclude is that in these patients spontaneous pain is associated with activation of the sensory cortex. It need not follow that normal conscious appreciation of painful peripheral stimuli concerns the sensory cortex.

\section{Summary}

Three cases are recorded in which partial resection of the post-central gyrus was undertaken for the relief of severe limb pain.

Observations are made on the electrical stimulation of the motor and sensory cortex of these patients. In each case stimulation of the appropriate area of the post-central gyrus reproduced the pain complained of by the patient, and relief followed the removal of this area of cortex.

The significance of these findings is discussed.

Our thanks are due to Dr. W. Ritchie Russell for his encouragement in this work, and for reporting these patients for treatment; to Miss Arnott for the illustrations, and to Miss F. M. Taylor for her assistance.

These patients were treated in the Military Hospital (Head Injuries), Oxford. We wish to thank MajorGeneral A. G. Harsant, Director of Surgery and Consulting Surgeon to the Army, for permission to publish.

\section{REFERENCES}

Adrian, E. D. (1941). J. Physiol., Lond., 100, 159.

Cushing, H. (1909). Brain, 32, 44.

Dusser de Barenne, J. G. (1924). Proc, roy. Soc. B, 96, 272.

Echols, D. H., and Colclough, J. A. (1947). J. Amer. med. Ass., 134, 1476.

Foerster, O. (1936). Handbuch der Neurologie, ed. Bumke, O., and Foerster, O. Vol. 6, P. 358. Berlin.

Gutiérrez-Mahoney, C. G. de (1944). J. Neurosurg., 1, 156.

- (1948). Surg. Clin. N. Amer., 28, 481.

Head, H., and Holmes, G. (1911). Brain, 34, 103.

Horrax, G. (1946). Surgery, 20, 593.

Lhermitte, J., and Puech, V. (1946). Rev, neurol, Paris, 78, 33.

Liddell E. G. T., and Phillips, C. G. (1950). Brain, 73, 125.

Marshall, J. (1951). Journal of Neurology, Neurosurgery and Psychiatry, 14, 187.

Penfield, W. (1947). Proc. roy. Soc. B, 134, 329

Penfield, W. (1947). Proc. roy. Soc. B, 134,

Rowbotham, G. F. (1946). J. ment. Sci., 92, 595.

Stone, T. T. (1950). Arch. Neurol. Psychiat., Chicago, 63, 739

Woolsey, C. N. (1943). Fed. Proc., 2, 55.

(1947). Ibid., 6, 437. 